\title{
Online Social Movements: Is It Me, You, or Us? What the Frame Says
}

\author{
Patricia J. Maxwell \\ Fielding Graduate University, United States
}

\begin{abstract}
Social movement research often views social movements through one of two lenses: a Durkheimian group perspective focused on social norms and behavior or a socio-psychological view focused on self-identity and group affiliation. This empirical study of the \#NeverAgain / \#MarchForOurLives student social movement that arose after the Parkland, Florida shooting in 2018, explores how the intentional framing of the experience launched a movement that integrated both research perspectives. Building on the foundational research of Leyens et al. (2000) and Vaes et al. (2002) on linguistic determinants of ingroup and outgroup associations, and in combination with Merola and McGlone's (2011) primary and secondary word lists, this study considers how posts in Twitter indicate a collective identity and if these themes are new and different from the frames of the Parkland students.
\end{abstract}

Keywords: Framing, Media Psychology, Social Media, Groups

\section{Introduction}

On the afternoon of February 14, 2018, Marjory Stoneman Douglas High School students were attending classes when a former student came on campus with an AR-15-style semiautomatic rifle and opened fire. Seventeen students were killed and seventeen others wounded. The social movement that arose from the Parkland shooting was fueled by Parkland students' passion to honor their fallen friends. Several students met the day after the shooting and discovered that they all had taken to social media already. They decided together that the primary frame for their movement would be gun control; knowing that it would be controversial and difficult, they made a pact to stick together and stay focused. They chose spokespersons. Then they picked two hashtags \#NeverAgain / \#MarchForOurLives (Cullen, 2019)

Focusing the movement in this way was an important strategic action. According to Flam (2015), ambivalence often the primary nation-wide reaction to tragedies like the Parkland shooting 


\section{Ecrhs}

\section{$2^{\text {nd }}$ International Conference On Research In HUMANITIES \& SOCIAL SCIENCES}

12-14 September, 2019

Rome, Italy

and this is often why change is so difficult She wrote that it takes extreme moral outrage to create new political horizons. The Parkland students were outraged and were ready to express themselves in an effort to create a new future. They formed the beginning of what became an international social movement that culminated with a rally that took place in Washington, D.C. on March 24, and at 800 locations worldwide (Jamison, Chason, \& Heim, 2018)

The intentional framing of the Parkland experience by the students through the use of the hashtags \#NeverAgain / \#MarchForOurLives took the event from a tragedy to a movement, and differentiated Parkland from several tragedies that have followed. It is proposed that the Parkland students' framed messages and personal accessibility on Twitter and through mass media had resonated with a much larger audience that eventually formed an autonomous collective identity, an anonymous and leaderless group in social media (Bennett, Segerberg, \& Walker, 2014), capable of developing message frames that had even greater psychological congruence.

This is a strategy that social movement researchers Barney and Schanffner (2019) also recommend. They suggest that a movement focus on the personal messages and stories by those most affected by mass shootings to cultivate public support for gun control policies. Not that this approach is without caution. A study by Lin et al. (2018), found a correlation between increasing attention to mass shootings and decreasing intervals between shooting incidences resulting in what is called the "contagious effect." Related or not, a little over three months after the Parkland shooting, another mass killing took place at a high school outside of Houston, Texas.

\section{Context: Guns in America}

The \#NeverAgain / \#MarchForOurLives movement focused on gun control, an issue seen by many in America as the most divisive issue in cultural and political history (Miller, 2019; Schuster, 2018). At one end of the public opinion spectrum is the "freedom frame." This argument is based on the Second Amendment of the United States Constitution which reads: "A well-regulated Militia, being necessary to the security of a free State, the right of the people to keep and bear Arms, shall not be infringed." This frame poses any type of gun control or limitations on gun ownership as an infringement on the basic freedoms upon which the country is founded (Miller, 2019).

There is a rarely spoken truth about mass shootings and the subject of guns in America; it has barely held public interest for the past two decades. According to Gallup editor Dugan (2018), two weeks after the Parkland shootings, social media mentions of guns or gun control as the most important problem facing the nation reached $13 \%$. This represented a 25 -year high. A month later, public mentions were down to $6 \%$. While this is a decline, it is a less steep decline than after previous mass shootings when mentions dropped to 0-1\%. By this measure, Dugan wrote, Parkland could represent a turning point in the gun control debate in that for the first time it is an issue that has not completely fallen off the minds of Americans. 


\section{Ecrhs}

\section{$2^{\text {nd }}$ International Conference On Research In HUMANITIES \& SOCIAL SCIENCES}

12-14 September, 2019

Rome, Italy

\section{Objective}

This study considers how themes that emerged autonomously in Twitter indicate a collective identity and if these themes are new and different from the frames of the Parkland students.

\section{Approach}

The psychological concept of framing forms the foundation of this study. Sociologist Erving Goffman (1974) credited anthropologist Gregory Bateson with coining the term framing in 1972. Goffman defined framing as the "schemata of interpretation" that enables individuals to organize, label, and create meaning around issues that seem to have no articulated shape $(1974$, p. 21$)$. It is Goffman's concept of framing that Benford and Snow (2000) say is what is used in the study of social movements today.

The psychological process of framing is a familiar one. It involves selecting one word over another when explaining an issue, highlighting aspects of one reality above another, and enhancing the salience of that reality over another (Entman, 2009). For instance, the following sets of phrases from case studies conjure different emotions and attitudes depending on age, political affiliation, cultural background, etc.: weapons of mass destruction vs. sustainable energy source (Woodward, 2004), spying vs. surveillance (Leistert, 2013), Keep America Clean vs. disposable containers (Rogers, 2005), flammable fabrics problem vs. stop smoking (Callahan \& Roe, 2012).

Social movements use framing, with varying success, to effectively set the tone and direction of their cause, to bring people to their cause and to defend their position. Using elements of semiotics, images and language, an organization may create attention-grabbing and psychologically appealing arguments that control the frame. The first group to control the frame also controls the argument (Lakoff, 2008).

Key cognitive structures at work in framing are automaticity and social identity.

Presented with a recognized stimulus or frame, individuals consciously, and often unconsciously, according to Kahneman (2011), go on auto-pilot in response. Cialdini (1984) describes this behavior as "click and whirr." Frames related to social identity appear to be some of the strongest and automatic of human behaviors. Bargh (1997, p. 246) wrote that this type of behavior is automatic to $99.44 \%$ accuracy, or "to an Ivory soap bar degree of purity." This was the case in Tajfel, Billig, Bundy, and Flament (1971) study. They discovered that participants, when asked to award points to one's own group or another, would award more resources to their own group. They were even willing to pay a cost to maximize the difference between their group and other groups, even in the absence of information or confirmation that their group existed. Tajfel 


\section{Ecrhs}

\section{$2^{\text {nd }}$ International Conference On Research In HUMANITIES \& SOCIAL SCIENCES}

12-14 September, 2019

Rome, Italy

and team concluded that the social desire to belong to a group, even one that does not exist, is powerful and unconscious.

Social media adds a new dimension to the concept of framing and the underlying psychological and cognitive structures that undergird its use in social movements. People using social media endorse or discuss issues with a larger community, whether they are members of the aggrieved group or not. This occurs in Twitter with the help of hashtags that make it possible for individuals to follow conversations and add their own comments. Consider these social movements and associated hashtags: \#BlackLivesMatter which developed in response to the killing of Trayvon Martin in 2013 (Clayton, 2018); \#MAGA (Make America Great Again) during the 2016 Trump campaign (Anderson, Toor, Rainie, \& Smith, 2018); and the \#MeToo movement that arose in 2017 against Harvey Weinstein's sexual-abuse allegations (Lee, 2018).

Social media has made it easier to share ideological and social frames instantaneously. Wellcrafted messages may go viral or in Twitter terminology become a "Trending Topic." This may occur in several ways, with one of the most common methods being the retweet where a message written by someone else is shared with an individual's social network, or may be shared with an added comment or opinion. The process is repeated by individuals in that person's network, sending the message far and wide in a matter of seconds in some instances. According to DiazBeristain et al. (2017), a retweet indicates subject interest and provides a level of confidence in the original publisher of the content. One such effort was the Ice Bucket challenge of July 15, 2014. The ALS Association knew nothing about this social media sensation until July 29, when ALS saw a $\$ 15$ million uptick in donations (Sifferlin, 2014). The combination of tweeted videos of buckets filled with cold water and ice poured over the heads of celebrities and social media influencers along with the hashtag \#StrikeOutALS proved to be powerful cultural transmissions, memes, that were easy for the public to remember and replicate within their own social networks.

The ALS experience illustrates how the act of retweeting may indicate frame resonance and emotional valence on the Twitter platform. This study of the \#NeverAgain is based on 1.2 million tweets, the majority of which are retweets, were collected between February 14, 2018 to April 16, 2018 using Twitter's application programming interface (API) within the academic application called DiscoverText. Posts that had more than ten thousand retweets were used in this study of the \#NeverAgain / \#MarchForOurLives social movement. The subset was collected after the larger dataset had been cleaned of fake accounts and posts that were not relevant to the movement but had used the hashtags as a means of boosting their posts readability. Examples of the latter were of vendors who were selling products, t-shirts etc., with the \#NeverAgain and \#MarchForOurLives in the post as a way of increasing visibility of their promotion. The remaining 106 posts analyzed, 36 were made by the Parkland-impacted students and teachers, the leaders of the movement, and the remaining 70 posts were made by those outside of the movement.

Just as the social desire to belong to a group is a powerful and unconscious human characteristic, so is the way in which humans assign emotional language to ingroups and 


\section{Ecrhs}

\section{$2^{\text {nd }}$ International Conference On Research In HUMANITIES \& SOCIAL SCIENCES}

12-14 September, 2019

Rome, Italy

outgroups. Leyens et al. (2000) conducted an experiment with an Implicit Association Task that included four quadrants, with words corresponding to positive primary, positive secondary, negative primary, and negative secondary emotions. The term primary emotion, as used here, has been described by Ekman (1992) and Sroufe (1979) as words children might use to describe emotions, such as joy, happy, angry and mad. In contrast, secondary emotions are terms that describe products of social construction and differentiate states of interaction. These are thought of as words adults would use to describe emotions, and they are considered more moral, less intense, and more internally developed (Kemper, 1987). Words in the secondary emotion list include pity, hope, hurt, suspicion and amazing.

Leyens et al. (2000) study enlisted university participants who were then shown sets of ingroup names in French, like François, and sets of outgroup names in Swahili, like Ashura, followed by words that could be positive primary or secondary emotions, and negative primary or secondary emotions. Half of the participants from each of the three universities were instructed to check as many defining words as they wanted for their ingroup. The other participants were told to check defining words for the outgroup. The researchers found that " $[\mathrm{w}]$ ithout awareness, people tend not to attribute secondary emotions to outgroups. They deny to others, even nonthreatening ones, the possibility of having such secondary emotions" (Leyens et al., 2000, p. 194).

Building on Leyens et al. and others work on infrahumanization, the \#NeverAgain / \#MarchForOurLives subset of 106 posts with more than ten thousand retweets apiece were analyzed for primary and secondary emotion word content using a master list of emotional words compiled for a study by Merola and McGlone's (2011).

This study differs from the Merola and McGlone (2011) study in that Twitter posts are limited to 160 characters and had limited references to emotional words. Therefore, each Twitter post was evaluated against five items: 1) inclusion of emotional words, primary or secondary 2) use of image or video 3) syntax, including caps which are meant to be read with emotional emphasis 4) references to celebrity and/or influencers with images, and 5) call to action. Total potential emotional valence score for a post could be five points. This emotional valence score, affiliation (whether the post was created by social movement leadership or other) and frame were analyzed using SPSS. Excel.

Additional tools used in the study were Maltego, DeDoose, Leximancer, Filemaker Pro, and

\section{Results}

Nearly twice as many posts, 70 total, were by Twitter users not associated with the \#NeverAgain / \#MarchForOurLives movement. Parkland students, teacher, and official organizers created the remainder 36 posts. The 106 posts were classified into nine message themes: 1) gun 


\section{Ecrhs}

\section{$2^{\text {nd }}$ International Conference On Research In HUMANITIES \& SOCIAL SCIENCES}

12-14 September, 2019

Rome, Italy

control 2) the enemy (NRA, etc.), 3) keep kids safe, 4) support the kids, 5) event success = social movement success 6) vote for change / politics, 7) message from the movement, 8) against the movement, and 9) no frame. The two winning frames were "keep kids safe" and "support the kids" with a total of 49 posts, 24 and 25 respectively. The next most referenced frame was "gun control" with 16 posts, followed by "vote for change / politics" at 13 posts, and closely followed by "event success = social movement success" with 12 posts. There were nearly twice as many secondary emotional words identified in the posts (16) to primary emotional words (9).

Total retweets from the 106 posts were more than 3.2 million. A post by a teacher with a small personal following around 500 in Twitter ended up with 166-plus-thousand retweets, taking first place in the study for the greatest number of content interactions. The emotional valence for the post scored four points. The post read: This kid wins the sign game \#marchforourlives. The included image was of a student carrying a sign that read "When I said I'd rather die than go to math class; that was hyperbole assholes."

The post with the second highest number of retweets was at 89-plus-thousand and encouraged readers to tune in to hear Emma Gonzalez' speech. What made this post emotionally compelling from several other posts on the same subject was the syntax that created the call to action. The post read: Emma Gonzalez. The entire speech. Watch. All. Of. It. \#MarchForOurLives. The authors of these two winning frames were outside of the social movement leadership.

The two top posts by the student leadership of the social movement were by Emma Gonzalez and Aly Sheehy. The post by Gonzalez on March 23 read: I have absolutely no words... Thank you not only for your service but for standing with us as we \#MarchForOurLives tomorrow. It was in response to a video posted on YouTube by a group called Veterans for Gun Reform that had endorsed the march. The post by Gonzalez reached 88-plus-thousand retweets.

Sheehy wrote on March 8 in response to a post by President Trump regarding how the FBI missed the signals regarding the Parkland shooter: 17 of my classmates are gone. That's 17 futures, 17 children, and 17 friends stolen. But you're right, it always has to be... The post reached 64plus-thousand retweets.

A three-way ANOVA was conducted to determine the effect of affiliation (ie. social movement leadership or general public), emotional valence, and frame resonance on overall retweets. There were six outliers assessed as a value greater than 3 box-lengths from the edge of the box. There was a statistically significant three-way interaction between affiliation, emotion and message frame, $\mathrm{F}(9,63)=2.099, \mathrm{p}=.043$. There was also a statistically significant simple twoway interaction between the social movement organizers and emotional valence, $F(10,60)=5.604$, $\mathrm{p}=0001$, and the same was true for others who were not part of the social movement leadership and emotional valence, $\mathrm{F}(12,60)=1.301, \mathrm{p}=0001$. 


\section{Ecrhs}

\section{$2^{\text {nd }}$ International Conference On Research In HUMANITIES \& SOCIAL SCIENCES}

12-14 September, 2019

Rome, Italy

Figure 1, left-side, shows the mean retweets by those not part of the social movement leadership. This affiliation garnered the overall greatest number of retweets for frames three and four, "Keep Kids Safe" and "Support the Kids" respectively. For the social movement leaders, right-side of Figure 1, indicates that the frames to note are six, seven and two. Frame six is a call to vote and follow the deeds of politicians, frame seven are messages from social movement leadership to the public about upcoming events, and frame two is a focus on the "enemy" which in this case was the National Rifle Association (NRA).

Figure 1: Mean Retweets by Frame and Emotion

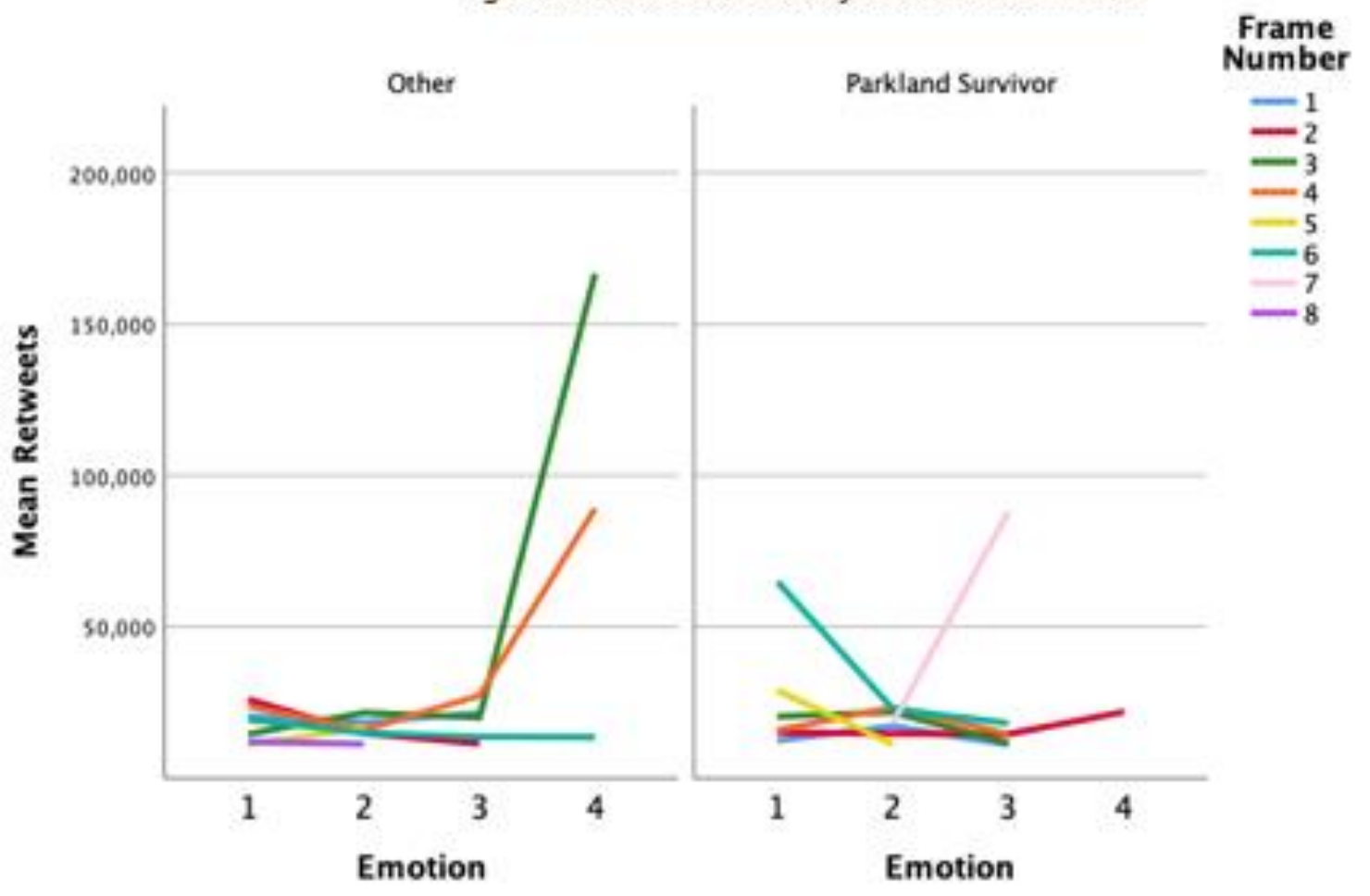




\section{icrhs}

\section{$2^{\text {nd }}$ International Conference On Research In HUMANITIES \& SOCIAL SCIENCES}

12-14 September, 2019

Rome, Italy

\section{Discussion}

What this study demonstrates is that an autonomous collective identity may form in social media, separate from leadership of a social movement or government. The frame that emerges may, and in this case is, unique to the collective and not the leadership of the social movement.

The frames by the \#NeverAgain / \#MarchForOurLives social movement leadership on gun control, voting, and in pointing out the enemy (NRA) (Cullen, 2019) did not garner as many retweets and with the exception of the frame on "fighting the enemy" tended to have lower mean emotional valence scores. Parkland students sharing their personal stories and experience on social media and through mass media kept this incident from becoming one more tragedy that faded into immediate history and out of the minds of Americans.

Frames created by individuals outside of leadership roles of the social movement \#NeverAgain / \#MarchForOurLives were retweeted in greater volume. The two frame subjects were about keeping America's youth safe and the need to support the next generation as leaders. These posts also had higher mean emotional valence scores than all other frames in the study. Frame resonance and emotional valence confirmed with retweet volume, suggests that a collective identity formed outside of the official leadership and formal organizational borders of the social movement.

The data used in this study are $15 \%$ of the whole. This leaves $85 \%$ of the social media conversation taking place in smaller networks, with post retweets of less than ten thousand apiece. Research of the remaining content, using the same methodology, may reveal a less cohesive ingroup (Leyens et al., 2000). Buechler (2016) defined powerful master frames as those that combine elaborate codes, external attributions, and high potency. It is possible that the master frame for the movement is one of those discussed in this study or that it remains to be discovered in the remaining data set. 


\section{$2^{\text {nd }}$ International Conference On Research In HUMANITIES \& SOCIAL SCIENCES}

12-14 September, 2019

Rome, Italy

\section{References}

[1].Anderson, M., Toor, S., Rainie, L., \& Smith, A. (2018). Activism in the Social Media Age. Retrieved from https://www.pewinternet.org/2018/07/11/activism-in-the-social-media-age/

[2].Bargh, J. A. (1997). The Automaticity of Everyday Life. In R. S. Wyer Jr. (Ed.), The Automaticity of Everyday Life: Advances in Social Cognition (Vol. X). New York, NY: Psychology Press.

[3].Barney, D. J., \& Schanffner, B. F. (2019). Reexamining the Effect of Mass Shootings on Public Support for Gun Control. British Journal of Political Science. doi:10.1017/S0007123418000352

[4].Benford, R. D., \& Snow, D. A. (2000). Framing Processes and Social Movements: An Overview and Assessment. Annual Review of Sociology, 26, 611-639. doi:0360-0572/

[5].Bennett, W. L., Segerberg, A., \& Walker, S. (2014). Organization in the crowd: peer production in large-scale networked protests. Information, Communication \& Society, 17(2), 232-260. doi:10.1080/1369118x.2013.870379

[6].Buechler, S. M. (2016). Understanding Social Movements: Theories from the Classical Era to the Present. New York, New York: Routledge.

[7].Callahan, P., \& Roe, S. (2012). Big Tobacco wins fire marshals as allies in flame retardant push. Chicago Tribune.

[8].Cialdini, R. B. (1984). Influence: The Psychology of Persuasion. New York, NY: HarperCollins Publishers.

[9].Clayton, D. M. (2018). Black Lives Matter and the Civil Rights Movement: A Comparative Analysis of Two Social Movements in the United States. Journal of Black Studies, 49(5), 448480. doi:10.1177/00021934718764099

[10]. Cullen, D. (2019). Parkland: Birth of a Movement. New York, NY: HarperCollins Publishers.

[11]. Díaz-Beristain, Y. A., Hoyos-Rivera, G.-d.-J., \& Cruz-Ramírez, N. (2017). Strategies for Growing User Popularity through Retweet: An Empirical Study. Advances in Multimedia.

[12]. Dugan, A. (2018). Guns Fall From Record High as Top Problem. Retrieved from Washington, DC: https://news.gallup.com/poll/232487/guns-fall-record-high-topproblem.aspx?version=print

[13]. Ekman, P. (1992). Are there basic emotions? Psychological Review, 99(3), 550-553.

[14]. Entman, R. M. (2009). Projections of Power: Framing News, Public Opinion, and U.S. Foreign Policy. Chicago, Illinois: University of Chicago Press.

[15]. Flam, H. (2015). Micromobilization and Emotions. In D. Della Porta \& M. D'iani (Eds.), The Oxford Handbook of Social Movements (pp. 264-276). Oxford, United Kingdom: Oxford University Press.

[16]. Goffman, E. (1974). Frame Analysis. Boston, Massachusetts: Northeastern University Press. 


\section{$2^{\text {nd }}$ International Conference On Research In HUMANITIES \& SOCIAL SCIENCES}

12-14 September, 2019

Rome, Italy

[17]. Jamison, P., Chason, R., \& Heim, J. (2018, March 24, 2018). March for Our Lives: Huge crowds gather for rally against gun violence in Washington The Washington Post.

[18]. Kahneman, D. (2011). Thinking, Fast and Slow. New York, New York: Farrar, Straus and Giroux.

[19]. Kemper, T. D. (1987). How many emotions are there? Wedding the social and automatic components. The American Journal of Sociology, 93(2), 263-289.

[20]. Lakoff, G. (2008). The Political Mind: Why You Can't Understand 21st-Century American Politics with an 18th Century Brain: Penguin Group.

[21]. Lee, B. H. (2018). \#Me Too Movement; It Is Time That We All Act and Participate in Transformation. Psychiatry Investig, 15(5), 433. doi:10.30773/pi.2018.04.30

[22]. Leistert, O. (2013). From Protest to Surveillance - The Political Rationality of Mobile Media: Modalities of Neoliberalism. Germany: Peter Lang GmbH, Internationaler Verlag der Wissenschaften.

[23]. Leyens, J.-P., Paladino, P. M., Rodriguez-Torres, R., Vaes, J., Demoulin, S., RodriguezPerez, A., \& Gaunt, R. (2000). The Emotional Side of Prejudice: The Attribution of Secondary Emotions to Ingroups and Outgroups. Personality and Social Psychology Review, 4(2), 186197.

[24]. Lin, P. I., Fei, L., Barzman, D., \& Hossain, M. (2018). What have we learned from the time trend of mass shootings in the U.S.? PLoS One, 13(10), e0204722. doi:10.1371/journal.pone.0204722

[25]. Merola, N. A., \& McGlone, M. S. (2011). Adversarial Infrahumanization in the Abortion Debate. Western Journal of Communication, 75(3), 323-340. doi:10.1080/10570314.2011.571651

[26]. Miller, S. V. (2019). What Americans Think About Gun Control: Evidence from the General Social Survey, 1972-2016. Social Science Quarterly, 100(1), 272-288. doi:10.1111/ssqu.12555

[27]. Rogers, H. (2005). Gone Tomorrow: The Hidden Life of Garbage. New York, NY: The New Press.

[28]. Schuster, K. (2018, August 11, 2018). 8 facts about gun control in the US: What you need to know DW. Retrieved from https://www.dw.com/cda/en/8-facts-about-gun-control-in-theus/a-40816418

[29]. Sifferlin, A. (2014). ALS Ice Bucket Challenge: How it Started. Time Magazine. Retrieved from http://time.com/3136507/als-ice-bucket-challenge-started/

[30]. Sroufe, A. L. (1979). Socioemotional development. In J. D. O'sofsky (Ed.), Handbook of infant development (pp. 462-516). New York, NY: Wiley.

[31]. Tajfel, H., Billig, M., Bundy, R. P., \& Flament, C. (1971). Social categorization and intergroup behavior. European Journal of Social Psychology, 1, 149-177.

[32]. Vaes, J., Paladino, M.-P., \& Leyens, J.-P. (2002). The lost e-mail- Prosocial reactions induced byuniquely human emotions. British Journal of Social Psychology, 41, 521-534.

[33]. Woodward, B. (2004). Plan of Attack. New York, NY: Simon \& Schuster. 